\title{
Article \\ Buddhist Modernism in the Philippines: Emerging Localization of Humanistic Buddhism
}

\author{
Aristotle Chan Dy
}

\section{check for}

updates

Citation: Dy, Aristotle Chan. 2022.

Buddhist Modernism in the

Philippines: Emerging Localization of Humanistic Buddhism. Religions

13: 220. https://doi.org/10.3390/ rel13030220

Academic Editor: Jack Meng-Tat Chia

Received: 16 December 2021

Accepted: 9 February 2022

Published: 4 March 2022

Publisher's Note: MDPI stays neutral with regard to jurisdictional claims in published maps and institutional affiliations.

Copyright: (C) 2022 by the author. Licensee MDPI, Basel, Switzerland. This article is an open access article distributed under the terms and conditions of the Creative Commons Attribution (CC BY) license (https:// creativecommons.org/licenses/by/ $4.0 /)$.
Chinese Studies Program, School of Social Sciences, Ateneo de Manila University, Quezon City 1108, Philippines; ady@ateneo.edu

\begin{abstract}
Mahayana Buddhism is well known for being successfully implanted in various cultures Chinese Buddhism, considered one of the three great religions of China along with Confucianism and Taoism, is a classic example. From China, Buddhism traveled further and, in the twentieth century, developed a particular way of engaging the world. Humanistic Buddhism, a particular form of engaged Buddhism that grew out of twentieth-century Chinese Buddhism, has been present in the Philippines since the 1990s and signaled a new phase in the growth of Buddhism in the country. In particular, the Philippine initiators of Foguangshan and Ciji did not limit themselves to the ethnic Chinese community from the outset, and both movements have achieved modest success in the last thirty years. By building on previous research with new inputs from key informants, this article explores the emerging localization of Foguangshan and Ciji in the predominantly Catholic Philippines, identifying the particular ways in which the two groups adapted their missions in the country.
\end{abstract}

Keywords: Buddhist modernism; humanistic Buddhism; localization; Ciji; Foguangshan

\section{Introduction}

At the beginning of September 2021, the Ciji 慈濟 headquarters in Taiwan launched the Yin-Cheng Distinguished Lecture Series on Buddhism to honor their founder, Zhengyan 證嚴, and her own Master, Yinshun 印順. The Ciji Buddhist Compassion Relief, known throughout the world for its work in charity and disaster relief, continues to recognize the inspiration received by its founder from her own mentor, who, along with Taixu 太虛, is widely considered as the greatest Buddhist reformers of Chinese Buddhism in the twentieth century. Likewise, the founder of Foguangshan 佛光山, Xingyun 星雲, was influenced by Taixu and put the latter's teachings into action in his worldwide order of male and female monastics devoted to promoting Buddhism through education and culture.

Ciji and Foguangshan are both forms of humanistic Buddhism that have operated in the Philippines for about thirty years since the early 1990s. In my earlier work (Dy 2015, pp. 97-100), I noted how their arrival in the country marked a departure from the traditional Chinese Buddhist temples that had served the relatively small Chinese community for over six decades. ${ }^{1}$ The traditional temples were run by Buddhist monastics from China who spoke only Chinese and could not attract the native Filipino population to temple life and practice. Further, I have highlighted humanistic Buddhism as a contemporary form of engaged Buddhism (Dy 2015, pp. 200-2).

Ciji and Foguangshan were not only modern in their use of language and available technologies to promote their vision. They were also exemplars of Buddhist modernism in the kind of Buddhism they presented in the Philippines. Humanistic Buddhism, to which these two traditions belong, focused squarely on this-worldly concerns in contrast to the funerary rituals that had long been a primary concern in Chinese Buddhism.

My doctoral research involved fieldwork surveying all the Chinese Buddhist temples of the Philippines, numbering close to forty. At that time, 2010-2011, I could not focus my 
analysis solely on Ciji and Foguangshan, but the historical information from that earlier study has been updated for this article. In the earlier work, I explored the links of Chinese Buddhism to the Chinese cultural identity of the overseas Chinese, doing so from my vantage point as an ethnic Chinese and a Catholic priest. Though I did not engage in comparative studies, I acknowledge this perspective as one that influences my analysis of Ciji and Foguangshan programs and activities.

My intention in the present study is to focus on the localization of these two organizations in the Philippines. I cite published sources about Ciji and Foguangshan, including materials from within the organizations, complemented by interviews with key informants. These interviews allowed me to use the self-understanding of Ciji and Foguangshan members in the Philippines and propose Buddhist modernism as a framework for understanding their initial localization in the Philippines. I point out instances of localization as I present the information on Foguangshan and Ciji, mindful that thirty years of contemporary history is only the beginning of an ongoing and vibrant process. I conclude by exploring possible trajectories that localization could take, considering the predominantly Chinese membership of both groups and the slow progress of translation into local languages of ideas and social structures. The Philippine experience of humanistic Buddhism contributes to the emerging discourse on global, contemporary Buddhism.

\section{Foguangshan and Ciji as Buddhist Modernism}

Jones (2003) identifies Taixu (1890-1947) and Yinshun (1906-2005) as the most influential monks to reform Chinese Pure Land Buddhism in the twentieth century. Taixu attempted to unite Buddhists across China around the idea of "Buddhism for human life" 人生佛教 as against the prevailing Buddhism that focused on the performance of funerals, "Buddhism for the dead." Instead of teaching people how to live in this world, the emphasis was on ceremonies and rituals to prepare for rebirth in the Pure Land and to pray for the dead. He hoped to shift the focus from other-worldly death rituals to this-worldly programs for the living. He advocated better Buddhist education and monastic organization, programs that Welch (1968) has described in the second of his trilogy on Buddhism in modern China.

Yinshun, a student of Taixu at the Minnan Buddhist Seminary in 1930, shared the desire to reform Chinese Buddhism after personally observing the disconnect between the philosophy of Early Buddhism that first attracted him and the rituals for the dead that he observed in his native Zhejiang. He brought Taixu's "Buddhism for human life" further by recognizing that Buddhism had ceased to put the focus on intellectual and moral self-cultivation to achieve Buddhahood. After all, such could be attained only by human beings, thus his preference for the term "Buddhism in the human realm" or "humanistic Buddhism" 人間佛教, the goal of which was to attain perfected humanity. This was against the deification of the buddhas that had taken hold in Buddhism.

Taixu, Yinshun after him, plus Xingyun and Zhengyan, the founders of Ciji and Foguangshan in Taiwan, belong to a line of Buddhist monastics who adapted Buddhism to the modern era. They employed the traditional Buddhist idea of "skillful means" to adapt to contemporary times. Rather than retreat to traditional practices in the face of massive change, they utilized the trappings of modernity in their approaches, such as media, technology, science, and education; they embraced modernism, the mindset that accompanies modernity, by valuing quantifiable results, pragmatism, and efficiency (Jones 2003, p. 127). The results of Buddhist practice had to be felt in the present world.

The ideas of Taixu and Yinshun, incubated in China, spread to Greater China-Taiwan, Hong Kong, Macau - and Southeast Asia in the second half of the twentieth century. This movement has been fittingly described by Chia (2020) as "South China Sea Buddhism," which is largely about the spread of Chinese Buddhist modernism through the monks who traveled to various countries in the region to spread their vision of reform. Chia (2020, pp. 31-32) situates this migration in the reform of Chinese Buddhism that Taixu 
and Yinshun were promoting, one that he links to the conception of Buddhist modernism articulated earlier by Hansen (2007) and McMahan (2008).

Hansen, writing on Buddhism and modernity in colonial Cambodia, describes the struggle of Khmer Buddhists to discover a way of behaving as good Khmer Buddhists in the colonial era. The ethical concern motivated the drive to engage with modernity, putting the emphasis on Buddhist concerns over "purification, authenticity, and nationalism (Hansen 2007, p. 3)." Concretely, this involved reinterpretation of Buddhist texts and the promotion of Buddhist education, a focus that heightened the significance of grounding everyday living on rational approaches to Buddhism. This shift to rationalism was a way of accommodating Buddhist and modern values (Hansen 2007, p. 13), and is one of many studies of Buddhist modernist movements in East and Southeast Asia that Heine and Prebish (2003) compiled in their anthology.

For his part, McMahan details the theme of Buddhist modernism not simply as any Buddhism that exists in the modern era, but those that "have emerged out of an engagement with the dominant cultural and intellectual forces of modernity (McMahan 2008, p. 6)." This is a very apt description of what Taixu was undertaking in Chinese Buddhism in the first half of the twentieth century. Humanistic Buddhism developed as a rational and scientific response to the prevailing practice of Buddhism in China. While Buddhist modernism is by no means a homogenous category, given its application to very diverse contexts in both East and West, McMahan notes the observation of Charles Taylor that two themes run through various discourses on Buddhist modernism, a "distinctively modern world-affirming stance, a sense that the locus of a meaningful life is not in another realm but in the way this life, everyday life, is lived, and second, the shift toward interiority, reflexivity, and self-scrutiny (McMahan 2008, p. 13).

As we shall see, Ciji and Foguangshan, with their focus on living out Buddhism in contemporary society, are expressions of Buddhist modernism in its particular manifestation as Chinese humanistic Buddhism. The histories and backgrounds of Ciji and Foguangshan are well-documented (Chandler 2004; Huang 2009), but this very brief outline of the Buddhist reformers who inspired their founders-Taixu for Xingyun, and Yinshun for Zhengyan-provide a historical context for the worldwide development of the two traditions of humanistic Buddhism that have spread throughout the world in the last three decades.

Foguangshan, founded by Xingyun in Taiwan in 1966, started with his efforts to organize a Buddhist choir, a magazine, academic institutes, a health clinic, and a large temple complex (Chandler 2004). He consciously made use of these modern means to promote Buddhism. Over the years, his experiences led to strategies that always sought to adapt to the times. Visiting the United States in 1976, he saw the opportunity to spread Buddhism by serving the overseas Chinese as their link to Chinese culture. Along with this cultural link, he wanted Foguangshan to create links of affinity with influential leaders, spark people's curiosity in the hope of planting the seeds of Buddhism, and localize Buddhist teachings and practice so as to attract more adherents (Chandler 2004). The four objectives of Foguangshan were later codified: to propagate the Dharma through culture; to foster talent through education; to benefit society through charity; and to purify human minds through spiritual cultivation (Wang 2020, p. 140).

With 200 temples in 33 countries, including large complexes in the United States and Australia, Xingyun holds that he has no particular strategies, which explains why these can change over time. In every place, he considers the needs of people as the top priority and tries to respond accordingly (Shih 2020, p. 112). In a paper published in 2020, Foguangshan monastic Shih Miaoguang identifies strategies, sometimes articulated as goals, that show how Buddhism is localized in each country. These include the advocacy for native-born abbots to head temples in their countries, accommodation for people to follow Buddhism along with their birth religions, teaching people in their own languages, and respect for and dialogue with other cultures and religions (Shih 2020, pp. 112-21). 
Ciji, also founded in 1966, is the biggest lay voluntary organization in Taiwan, and like Foguangshan, its growth is largely due to the charisma of the founder, Zhengyan. While Xingyun had fled to Taiwan after the Communist Revolution in China, Zhengyan was a Taiwanese native and experienced many personal struggles to become a Buddhist monastic. She was brought up by an uncle who was childless at the time of her birth. At a young age, she helped run her father's opera theater business, developing business skills that proved useful later when she was organizing Ciji.

In her early 20s, Zhengyan was attracted to Buddhism and spent a few years trying to find the right path for herself. She first shaved her head in a lay Buddhist's household, but following government rules governing formal recognition of monastics, realized that she needed to have a formal tonsure master. A chance encounter with Yinshun led to her ordination and later studies under him. His ideas on humanistic Buddhism, coupled with the challenge put to her by Catholic nuns and an experience of inadequate hospital care for the poor, led to her decision to found a Buddhist charity (Yao 2012, p. 65ff.). Starting with only thirty women around her, the charity slowly grew in Taiwan. Grassroots fundraising was done by Zhengyan's disciples, giving all people regardless of economic class an opportunity to give. By 1978, a project to build a hospital in Hualian was underway, and by the late 1980s, other major projects in education and culture were also established throughout Taiwan. In the 1990s, Ciji began disaster relief operations abroad. The Taipei branch became the headquarters for print, TV, and radio. Organizational structures were established to expand membership.

Ciji began with four overarching missions - charity, medicine, education, and humanistic culture (Honasan 2019, p. 40). As these missions expanded, the organization responded to more urgent needs, giving rise to four more missions-bone marrow donation, community volunteerism, environmental protection, and international relief. Together, these missions are known as the Eight Footprints (Honasan 2019, p. 53). As of 2019, Ciji is said to have "millions of members" donating small amounts regularly in 58 countries and close to 100,000 volunteers (Honasan 2019, pp. 39, 56).

The work of Foguangshan and Ciji overseas has received scholarly attention. Reinke (2018) explores the religious and secular development of Foguangshan through the lens of the Hsi Lai Temple in California, its first overseas temple, and the headquarters of its lay arm, the Buddha's Light International Association (BLIA). Ciji's work in Canada (Laliberté and Litalien 2010), Malaysia (Huang 2014), Singapore (Tan 2008), the United States (Lee 2003), and the Philippines (Lau and Cornelio 2015) have been explored from various perspectives. The latter presents the participation of Filipino volunteers in the work of Ciji as "aspirational" rather than religious in their hopes of building a better life for themselves and others.

Foguangshan and Ciji are both forms of humanistic Buddhism that demonstrate Buddhist modernism. Stuart Chandler describes the modernist agenda as a "three-stage historical schema: original, genuine tradition (i.e., that practiced in the early community); spurious tradition (i.e., that promoted in subsequent, especially recent, centuries); and modern tradition (i.e., that which contravenes the false practices of spurious tradition to regain the underlying spirit of genuine faith) (Chandler 2004, p. 68)." While they differ in emphasis, both Foguangshan and Ciji, in their vision and mission, are reactions to the excesses of Chinese Buddhism and traditional religion as articulated by Taixu and Yinshun. Both aspire towards relevance and authenticity to their own historical setting, as against the accrued ideas and practices that had accumulated in traditional Chinese Buddhism. This direction for Chinese Buddhism runs parallel to the trajectory of Buddhist modernism described earlier in the work of Hansen and McMahan.

Foguangshan (Chia 2015) and Ciji have not shied away from using all modern means of technology to spread the Dharma in the second half of the twentieth century, using the internet, radio, TV, and print media to spread their message and attract adherents. In the worship style adopted by each community, there is simplicity and elegance, in stark contrast to the perceived excesses of traditional temples. The monastics (in the thousands 
for Foguangshan, much less for Ciji) do not depend on funeral rituals for their income; instead, they are trained in the particular skills needed to advance their respective missions.

Focusing on Western Buddhism, Lopez (2002) uses the term "modern Buddhism" to describe a spectrum of developments in some Buddhist traditions since the late 19th century in reaction to colonialism and modernity. Like Zhengyan, who was challenged by the criticism she heard from Catholic nuns and resolved to make charity a capstone of her work, these developments were also in response to greater interaction with the Christian West. For Buddhists, such developments include: (1) the interpretation of Buddhist doctrine in accordance with these "modern" ideas, and the view that this interpretation is a return to the form of Buddhism practiced at the time of the Buddha; and (2) the belief that this is an unadulterated form of Buddhism, from which superstitious elements and other later additions have been removed. Furthermore, (3) it is clear of any sectarian division; (4) weight is given to the philosophical, rather than ritualistic, nature of Buddhism; (5) the practice of meditation is emphasized; (6) it is considered to be in accord with science; (7) it has strong lay-Buddhist and (8) female involvement; and (9) it is also concerned with social welfare.

The earlier outline of Foguangshan and Ciji's backgrounds show how they fit very well into the conceptions of Buddhist modernism that we have described earlier, and the nine indicators used by Lopez to describe modern Buddhism, especially in regard to the primary desire to return to the original teaching of the historical Buddha, a movement that Chandler (2004) and Pacey (2005) also note for Foguangshan. Humanistic Buddhism is quick to point out that the historical Buddha was a human being who attained enlightenment in this world after witnessing sickness, old age, and death and was proposing a middle way to the extremes of Brahmanism during his time. The rituals for divination or geomancy that have penetrated Chinese Buddhist temples are not found in Foguangshan and Ciji. Instead, there are programs of education and culture to impart Buddhist ethics and way of life. Personal spiritual cultivation is espoused, and science is trusted to alleviate human suffering, as evidenced by Ciji's medical missions and hospitals. While Foguangshan has many monastics, its lay arm has just as many lay members, and Ciji's membership of millions is largely laypeople, the majority of them women. As this study will demonstrate, Foguangshan and Ciji brought their humanistic, modern Buddhism to the Philippines and adapted it further to fit the particular circumstances of the largely Catholic country.

Granting the modernist approaches of Foguangshan and Ciji worldwide, what is the particular texture of their localization in the Philippines?

\section{Foguangshan in the Philippines}

Between Foguangshan and Ciji, it is the former that has articulated an explicit strategy of localization. Though it taps links to Chinese culture to work among overseas Chinese, this is seen only as an entry point. Xingyun is often quoted as a champion of localization, citing Chinese Buddhism itself as the greatest example of foreign teaching taking root successfully in China (Wang 2020, p. 139). Localization can therefore take on many forms, adopting "skillful and expedient means which are relevant to modern society in order to be effective ..." (Wang 2020, p. 140). Especially in Western societies, there is a conscious awareness that Dharma propagation must not be seen as a cultural invasion.

An anecdote that is frequently shared about Xingyun is about his experience of delivering a lecture at Cornell University in New York. Buddhist scholar John McRae approached him after the lecture with this comment: "It is okay to say you are here to propagate Buddhism, but the constant mentioning of Chinese culture makes it sound like you are here to conquer American culture (Wang 2020, p. 142)." This experience gave Xingyun the insight that localization requires assimilation into local society and great respect for the languages and cultures of others. Therefore, for Western societies, translation of Buddhist texts, cultivation of local Dharma masters, and other cultural activities must be carried out to introduce Buddhism. 
However, the distinction between Buddhist teaching and Chinese culture is difficult to maintain in the work of Foguangshan. In his paper on localization as the method for internationalizing Buddhism, Wang Bin ends by saying that Buddhism is a key component of Chinese culture and is an effective path for advancing the globalization of Chinese culture (Wang 2020, p. 151). Xingyun has a vision of Buddhism that is localized, but since Foguangshan is so closely linked to Chinese culture and even uses this link as an entry point to attract overseas Chinese, it remains to be seen how "global" Foguangshan will be in the future.

In the Philippines, Foguangshan started with the active participation of the local Chinese community. A Chinese couple, Paterno and Rosita Luym, constructed the Ci'en Temple 慈恩寺 in Cebu City in 1988 to honor Paterno's mother, a devout Buddhist (Dy 2015, p. 79). Knowing that they needed Buddhist monastics to run the temple properly, the couple made several trips to Taiwan to request Foguangshan monastics to reside in Cebu and accept the administration of the temple. Xingyun was moved by the couple's desire to honor their mother and sent two female monastics to take charge of the temple in Cebu (Shih 2020, p. 127). One of them, Yongguang 永光, became abbess and today is the Chief Abbess of all four Foguangshan centers in the Philippines.

Knowing that Foguangshan had accepted to be formally present in Cebu, Buddhist devotees in another Central Philippine city, Bacolod, led by Chen Suzhen 陈素珍, quickly visited Cebu and renewed the invitation for Foguangshan to be present in Bacolod as well. As early as 1985, exploratory talks had begun between the Fazang Temple 法藏 寺 in Bacolod, one that combined Buddhism with folk religion, and Foguangshan, but Foguangshan ultimately decided not to accept responsibility for the temple. With the development in Cebu, Chen mobilized her network and purchased property, including a wooden building, to start a new temple. In 1991, she led a delegation to Taiwan and had an audience with Xingyun, offering total control of the temple to Foguangshan. Xingyun accepted and gave the temple its name, Yuantong Temple 圆通寺 in honor of the bodhisattva Guanyin. In 2004, the construction of a modern temple was completed, and it included facilities for in-house camps and other activities.

Iloilo, a city that neighbors Bacolod, has a few privately administered folk temples. Buddhist devotees began inviting Yongguang to visit their city and give talks, and also traveled to Cebu or Bacolod to attend chanting services and other activities. When the lay arm of Foguangshan, the Buddha's Light International Association, was being organized in the Philippines in 1995, a chapter was formed in Iloilo. This group eventually established a Foguangshan center on the third floor of an apartment building which came to be known as Foguang Yuan 佛光缘.

Interestingly, Foguangshan had more humble beginnings in the capital, Manila. Soon after the temples in Cebu and Bacolod had been established, devotees in Manila invited Yongguang for activities in the big metropolis. In 1992, Yongguang started by leasing a small apartment in Manila's Chinatown and presented it to the community as the Manila Chan Center 馬尼拉樿靜中心. After just one year, officials from Foguangshan's overseas affairs unit visited Manila and decided that the capital had great potential for the expansion of Foguangshan. With support from Taiwan and some local devotees, a property was purchased on Pablo Ocampo Street, which included the building of the former Russian Embassy. This became known in Chinese as Wannian Temple 萬年寺 or the Mabuhay Temple. $^{2}$ The present ten-story building was completed in 2010 and is the headquarters of Foguangshan in the Philippines.

Unlike the traditional temple communities founded by monastics from China, most of the Foguangshan monastics in the Philippines speak English and are able to work beyond the Chinese community, although by their own estimation, $80 \%$ of their followers are ethnic Chinese (Dy 2015, p. 59). Foguangshan broke the biggest barrier to the growth of Buddhism in the Philippines, that of language; this factor alone is a major manifestation of Buddhist modernism as a practical approach to spreading Buddhist teaching. 
In 2007, the Ci'en Temple community in Cebu produced a musical on the life of the historical Buddha entitled Siddhartha. The musical was performed before thousands in the Philippines and Taiwan, prompting Xingyun to suggest that the arts would be a key platform for propagating the Dharma. The Foguangshan Academy for the Performing Arts was subsequently established at the temple in Cebu.

In Bacolod, the Humanistic Academy of Life and Arts was established to organize camps that lasted up to three months for young adults on gap years or were in between jobs to spend some time living a Buddhist lifestyle and learning arts and crafts.

With its high-rise building that does not resemble a temple at all, the Mabuhay Temple in Manila is actually a multi-purpose building. The worship area is on the second floor. The ground floor has a tea house, exhibition halls, dining hall, and meeting rooms. The upper floors house a museum and art gallery, meditation hall, lecture rooms, library, the Guang Ming College, a columbary, and monastic quarters.

In 2014, Guang Ming College opened within the temple premises, offering undergraduate degrees in Buddhist Studies, Theater, and Performing Arts. The students are recruited from different parts of the country and are given full scholarships to live and study in the temple premises, following a vegetarian lifestyle and some degree of isolation from the world. In 2021, the school moved to its own campus in Tagaytay City, a few hours' drive south of Metro Manila.

The thread that ties together the works of Foguangshan in education and culture is the Three Acts of Goodness (TAG) framework that Xingyun launched in 1998. The three acts are to do good things, to speak good words, and to think good thoughts. On the face of it, these are very general moral principles to live by, but in the Foguangshan understanding, as explained to me by Shih Miaojing 釋妙淨 (2021), abbess of the Mabuhay Temple, the practice provides for good karmic retributions by emphasizing three aspects of personal and communal cultivation. The TAG aspects are based on Buddhist teaching, even if this is not highlighted too much.

The TAG message runs through many programs of Foguangshan, such as their Chinese language classes that are named after the TAG; it is the theme of summer youth camps and is the content of brief talks that are given at the beginning of major cultural and charitable activities. Guang Ming College and the institutes for performing arts use TAG as a framework for what they do. ${ }^{3}$

As recounted to me by Miaojing (Shih 2021), in 2016, Foguangshan entered into a partnership with the Philippine Department of Education to bring TAG to public schools. Officials from the education department had visited Taiwan and observed the effect of the TAG campaign on the calm and service-oriented behavior of students. They requested Xingyun to bring the TAG campaign to Philippine schools. Made part of the values education curriculum, TAG was introduced initially at remote and small schools where it could take off more quickly. Foguangshan volunteers do the initial training of teachers, and schools are later invited to submit applications for small grants to implement TAG projects in their school or community. A wide variety of activities that fall under "doing good deeds" are thus supported by Foguangshan. The schools submit an annual report and request for the following year's grant. As of 2021, there are 160 schools that belong to the program. The temple is quietly spreading Buddhism-inspired ideas among Filipino youth (Shih 2021).

As is true of all the four temples, chanting services are organized at the Mabuhay Temple on the first and fifteenth of the lunar month, Buddhist feast days, as well as every weekend to follow the Christian work and leisure cycle of the Philippines. This in itself is an act of localization. However, the chanting services are by no means the primary activity in the temples. Especially in Manila, the temple organizes lectures, exhibits, dance and art classes, and other activities that promote various aspects of Foguangshan Humanistic Buddhism, such as vegetarianism and ecology. Between my original fieldwork in 2010-2011 and 2021, the scale of activity has increased and diversified. 
Shih (2021) says she occasionally presides at Buddhist weddings at the Mabuhay Temple. It is usually requested by the temple's most ardent devotees, but the fact that it is possible is a great inroad into the Filipino way of life. Unlike many countries where civil and religious marriage rites are held separately, the norm in the Philippines is a church wedding. Catholic priests and Christian pastors have licenses from the government to perform weddings so that the ceremony fulfills both civil and religious requirements. That the Mabuhay Temple is able to do the same is an act of localization that may bear more fruit in the future.

Funeral rituals normally keep religious professionals very busy, but at Foguangshan, these are done only upon request by members. The monastics do not accept any stipends for these practices, in contrast to traditional temples. The columbary in the temple premises, again a common way of generating income in religious establishments, is not open to the public and serves devotees only. On Saturdays, the temple holds simple prayers for the dead without the elaborate offerings seen elsewhere. These controlled practices in regard to funerary rituals seem to go against the idea of localizing by responding to local needs, but localization is a dynamic process after all. Foguangshan, with its emphasis on Buddhism in the human realm, has resisted the temptation to go along with local customs that put so much emphasis on funerary rituals. Miaojing says that even funerals and inurnments are done "for the living" rather than the dead (Shih 2021). This is a very precise application of Buddhist modernist ideas. For instance, at a funeral service in December 2010 for a senior monk at the Un Siu Temple in Manila, I personally witnessed the Foguangshan monastics very politely refusing the red envelopes offered to them for their presence and participation in the service. Putting rituals for the dead in its proper place is an example of strong advocacy for humanistic Buddhism.

If we consider Shih's (2020) description of strategies for localization in Westernized societies, it is evident that in the Philippines, it is the legitimation of having equal devotion to two religious beliefs that has been a big help in gaining adherents. The majority of Chinese Filipinos are officially Christian (Ang-See 1997, p. 57). Catholics, in particular, are known to combine church practice with some level of temple involvement. While Church authorities are aware of this, no formal position has been taken on the matter. In contrast, Foguangshan welcomes all to participate in their activities. No one is required to convert to Buddhism, and this is especially relevant in the TAG campaign in public schools.

Xingyun has explicitly taught that it is desirable to follow two traditions simultaneously. Without going into possible doctrinal conflicts, for example, on the teaching about rebirth and multiple life cycles, Xingyun simply says that the important thing is to assist in improving morality and quality of life and purifying human minds. ${ }^{4}$

There is, therefore, a lot of freedom for people to participate in Foguangshan activities even if they also profess to be Catholic and observe major Catholic rites such as baptism, marriage, and funeral ceremonies. There is a wide spectrum in which people can locate their particular mix of Catholic and Buddhist practices. It is not uncommon to hear Buddhists say that Guanyin and the Virgin Mary are "the same" because of their shared characteristics (Dy 2015, pp. 158-60). That Foguangshan regularly hosts dialogue sessions with Catholic groups, welcoming students, priests, and nuns from Catholic institutions who are studying interreligious dialogue, to its temples further supports the idea that there is harmony between Buddhism and Catholicism. Such an open and welcoming attitude to Catholicism has been a key ingredient in the localization of Foguangshan in the Philippines. In my online interview with Correa (2021), former president of Guangming College, she agreed with me that Foguangshan work in interreligious dialogue is another manifestation of Buddhist modernism and added that the organization is against strict sectarianism and discrimination.

Xingyun envisions a time when Foguangshan temples will be headed by local monastics (Shih 2020, p. 113), a vision shared by Yongguang for the Philippines, but this may take many more years before it becomes a possibility in the Philippines. The monastics sent to 
the Philippines so far have all been female, and no local person has yet pursued a monastic vocation.

The Buddha's Light International Association (BLIA) is the lay arm of Foguangshan worldwide. It has seventeen local chapters with a total of 600 members in the four cities where Foguangshan is present in the Philippines (Shih 2021), and each chapter organizes its own activities for its local area. At official events, lay members wear a bright yellow Foguangshan vest over their street clothing. One activity that they promote is to celebrate the Buddha's birthday at local shopping malls. A statue of the child Siddhartha is displayed prominently, and people are invited to "bathe" the Buddha with a scoop of water, symbolizing prayers for peace and wellbeing. The statue, reminiscent of the Sto Niño, the Christ Child that is popular among Filipino Catholics as the first Catholic image brought by the Spanish colonizers, evokes parallels between Jesus and Siddhartha. The activity is an informal way of making Buddhism better known in mainstream society.

A volunteer who leads a youth group of thirty members says that it is not enough for the monastics to speak some English. They also need to understand Westernized society more because that is the context of the Philippines. The son of a devotee, So (2021), remembers always being brought to the temple as a child and once being scolded by a monastic because he had fallen asleep during a service. He attended a Catholic school and found the Catholic faith comforting as a child, especially when his father died, but in high school, after attending a youth camp at a Buddhist college in Taiwan, he chose Buddhism as his personal philosophy and religion. After graduating with a university degree in corporate management, he was persuaded to work at Guang Ming College as it moved to a new campus. ${ }^{5}$

Having spent much time at the Mabuhay Temple when he was growing up, he thinks that much more needs to be done in translating the teachings into local languages, and not just English. As elsewhere in the world, he says, Foguangshan is a Chinese environment even if it claims to be open to all. The pioneer devotees and the monastics are used to interacting with fellow Chinese, even if these are not Chinese-speaking, and may have biases against non-Chinese that prevent the temple from being authentically open to local people. The Philippines is a poor country, after all, but So feels that the poor people cannot just walk in, inquire, and participate in the temple's activities. There are socio-economic dimensions to the barrier of language.

To further explore the theme of localization and the prospects for cultivating a younger generation of Buddhist-inspired leaders, the growth of Guang Ming College (GMC) in its first seven years of operation may be instructive. Correa (2021) shares that the college had about 80 students in its first few years of operation, but only 36 graduated. Coming from financially challenged families, some of those who dropped out opted to start working in order to support their families. Others found the temple lifestyle, including vegetarianism, the prohibition of mobile phones, and other restrictions, difficult to sustain over a number of years. So (2021) says that some families also kept worrying that their children were being converted. Those who graduated with degrees in Buddhist Studies or the Arts did not have an easy time finding employment. A few were hired by the temple or proceeded to further studies in the arts, but others accepted jobs such as call center agents or tried to go abroad doing unrelated work.

Tan (2021), an anthropologist by training and one-time Chancellor of the University of the Philippines, became president of Guang Ming College in 2021, just as it prepared to move to the new campus in Tagaytay. He has secured permission from Foguangshan headquarters in Taiwan to redesign the Buddhist Studies degree into one called Life Education, to be able to train students in a wider range of skills like counseling, guidance, hospice, and palliative care, all with Buddhist foundational principles. This will help graduates fill concrete needs in society. The degrees in the performing arts are still around, but a new one on Sports Science will be introduced. To address the dropout rate, the course is structured as a two-year associate degree, and only those who are serious about completing an undergraduate degree proceed with two more years of studies. 
Thanks to his background in anthropology, Tan has also started encouraging faculty and students to translate Buddhist terms into various Philippine languages. This effort at translation, identified earlier as a key element of localization, is now underway, and Tan hopes to systematize it in the near future.

\section{Ciji in the Philippines}

Yinshun served as abbot of the two biggest temples in Manila for two years (1958-1960), and other monks in the Philippines trace their Dharma lineage to Taixu or his students (Dy 2015, p. 33). The background of these monks, and their propagation of the Dharma in the Philippines, can be considered the early seeds of humanistic Buddhism in the country, albeit limited to the Chinese community due to the language barrier.

The information that follows comes from Ciji's internal publications, complemented by new interviews and identification of localization strategies. ${ }^{6}$

In June 1991, after a series of small explosions in the preceding months, Mt. Pinatubo in the main Philippine island of Luzon erupted in one of the most disastrous natural calamities of the twentieth century. Hundreds of thousands of people were displaced, and a few hundred died. Volcanic ash buried entire villages. It would take years for the affected areas to recover. Later that year, Zhengyan, the disciple of Yinshun, was awarded the Magsaysay Award, Asia's version of the Nobel Prize, for the humanitarian work of Ciji in Taiwan over 25 years. She was unable to travel to Manila to receive the award, but she decided to donate half of the award money to assist those who were displaced by the eruption of Mt. Pinatubo. For most Filipinos, it was their first exposure to the charismatic Buddhist nun, described by the award-giving body as the Mother Teresa of Asia.

A year later, a Taiwanese lady named Linda Chua, who had been living in Manila for more than fifty years and frequented some of the city's temples, was searching for spiritual direction. She read some materials on Ciji. Her neighbor, Rosario Jacinto, introduced her to Hsu Chin-Feng, a commissioner or full-fledged member of Ciji who was promoting Ciji in Manila. Hsu invited Chua to visit the Ciji headquarters in Hualian and arranged an audience with Zhengyan. The latter sent her home with more materials and asked her to return in six months to be admitted as a commissioner. Chua felt inadequate but assisted Hsu in her fundraising activities in Manila. By 1994, 200 donors had made pledges, and a group traveled to Taiwan to present the donations to Zhengyan, who told them that they need not continue raising funds for the headquarters of Ciji. They should instead keep donated funds to start projects in the Philippines. That is how Ciji Philippines was established that same year, with Chua serving as the first Chief Executive Officer.

The new group started by visiting hospitals in Manila and helping charity patients buy their medications. One of the first volunteers, Dionisia Qua, had a physician-son, Josefino, who invited his colleagues at the Chinese General Hospital to volunteer at the first medical mission in Baguio City, a city in the north of Luzon island. Jacinto, who had a hand in making the introductions that led to the establishment of Ciji in the Philippines, was a registered nurse who joined the early missions. It was the first of many more medical missions to remote places where people had never seen doctors offering free surgeries, medical consultations, and providing medications. In an interview with me, Qua (2021) recounted how he became a master of innovation, borrowing the classrooms of small Chinese schools in various cities to convert them into makeshift surgeries. Conditions were never ideal, and there were always too many people asking for help, but the volunteers learned to work with whatever resources were available. This became a hallmark of Ciji's localization in the Philippines - the ability to perform surgeries in makeshift facilities and make do with whatever equipment was available.

The medical missions earned the praise of many, and when doctors at the headquarters in Taiwan heard of them, they were very incredulous. Zhengyan promptly asked them to visit the Philippines and witness the missions for themselves. The verdict-the missions look "ridiculous," but the model is working. From 1995 to 2000, quarterly medical missions offering surgeries were brought to places that needed them most, each mission serving 
about 8000 patients. Qua (2021) says it was only when the government began insisting that surgeries could only be done in hospitals that the unique model of Ciji had to adapt to government regulations.

The missions became a hallmark of Ciji service, with a focus on reaching places that are underserved by medical professionals. In 1998, a mission in Zamboanga, in the southern part of Mindanao island, led to the mobilization of a network of volunteers that made it possible to establish a liaison office in the city by the year 2000. In 2004, the office collaborated with the local government hospital to set up a leg prosthesis and rehabilitation center to serve the needs of poor amputees using inexpensive prostheses designed in Jaipur, India. The center has served amputees from many other cities and has also trained amputees to make and maintain prostheses themselves as a source of livelihood. This first center in Zamboanga was followed by an eye center established at the same hospital in 2008. Thousands of people have availed of free cataract operations at the center.

Liaison offices were also established in Cebu (2000) and Bohol (2014), after volunteers during natural disasters were able to sustain operations for an office to be maintained. As a purely voluntary organization, a key element of Ciji localization is to align with the conditions on the ground to determine the extent of its operations. This has made it possible to pursue both short-term medical missions and long-term offices that organize ongoing projects. These Buddhism-inspired works in science and medicine are very concrete and modern responses to the particular needs identified by Ciji in the Philippines.

Medical professionals who volunteer with Ciji are organized as the Ciji (Tzu Chi) International Medical Association (TIMA). Since 1996, Zhengyan has invited the leaders to visit her every year in Taiwan. Qua, along with the current head for the Philippines, Dr. Antonio Say, have participated in the annual fellowship activity with Zhengyan.

Ciji volunteers belong to two categories as signified by their uniforms. Grey shirts are worn by those who are still in training, usually for a period of two to three years. The signature blue shirt is worn by those who have been inducted as Commissioners (women) or Faith Corps (men), volunteers who have not only received training but accept to live by the ten precepts. ${ }^{7}$ For formal occasions, ladies wear a uniform Chinese dress, and men wear a suit. There are 284 commissioners, 63 Faith Corps, and 600 volunteers in the Philippines, according to the Ciji Philippines spokesperson Lao (2021). Medical professionals who volunteer with the TIMA are not necessarily formal members of Ciji.

In 2006, the Ciji Great Love Campus was opened in Sta. Mesa, Manila, on a 4.5-hectare property purchased from a Catholic congregation of nuns that moved their huge centers for educating poor youth elsewhere. The campus became the headquarters of Ciji in the Philippines and includes an eye center and dental clinic, among other facilities. It has also become a place for supporting education, as the young people provided with scholarships for basic education or university studies gather at the center for monthly classes on humanism, values, and crafts.

Aside from supporting the studies of disadvantaged Filipino youth, Ciji Philippines has invested much in the propagation of Zhengyan's Buddhist teachings. A bi-monthly publication called Ciji World is produced regularly in English and Chinese, and materials are also published as contributed articles in Chinese newspapers. Zhengyan's aphorisms are available as booklets, some of which have already been translated into Tagalog. These efforts at publication, especially in the local language, are key indicators of modernist localization. Ciji publications, along with dictionaries and school supplies, have been distributed in numerous public schools, an activity that is regularly undertaken.

To make the Da Ai (Great Love) television channel of Ciji accessible in the Philippines and throughout the world, Ciji pioneer Francis Chua launched the Mabuhay satellite from the Philippines in 1997. Subsequent launches ensured that there would be no technical obstacle to the accessibility of the channel.

Ciji Philippines has also staged plays to promote the Buddhist scriptures favored by Zhengyan. The Sutra on Profound Gratitude to Parents, a treatise on filial piety, has been produced as a major stage production twice, in 2002 and 2012. If not for pandemic 
restrictions, Zhengyan's own commentary on the Compassionate Samadhi Water Repentance 慈悲三昧水忓 would have been staged with the involvement of a thousand performers in 2020.

To organize the youth, an annual summer camp is organized in Taiwan for young people to learn about vegetarianism and environmentalism as well as the teachings of Zhengyan (Nakar and Vizcarra 2010). From a pioneering group of twelve, the youth group now has 500 members. It was thanks to the youth that Ciji Philippines began an earnest campaign to promote recycling. Youth groups would go to big events, collect and sort plastics, metal, glass, aluminum, and other scraps for recycling. By 2017, 292 recycling stations where the general public could bring their recyclable scraps had been established in Metro Manila, including fifty on the premises of public schools. With technology from Taiwan, the scraps have been transformed into everyday items like bags and rugs. The environmental activities have been particularly attractive to young people who feel the urgency of environmental protection much more than their elders.

While much of the work of Ciji is done in local communities and does not attract media attention, the disaster relief work of Ciji has often been in the spotlight. In a poor country like the Philippines, where many people live in houses made of light materials in densely populated communities, fires often break out and are reported in the news. Ciji is always quick to respond, assisting evacuated people with blankets, food, and other items to help them rebuild their lives. For example, this was done in 2009 when candles caused a fire in a Quezon City slum area and left 700 families homeless. Manila's port area, which includes a huge garbage dump, is home to thousands of families. Fires are a common occurrence, but Ciji does not tire of providing relief whenever needed.

Combining concern for the youth with disaster relief, Ciji has rebuilt public school buildings in Tabaco, Albay (2006), and Compostela Valley, Maguindanao (2012), after strong typhoons hit the areas and damaged many structures. For instance, in 2009, disaster relief took another form when a powerful typhoon named Ketsana raged for days and left large parts of Metro Manila flooded. Houses were inundated, and people were left stranded on their rooftops. Ciji volunteers, in their iconic white and blue uniforms, mobilized quickly to provide relief and start a massive cleanup project. In what is perhaps their most unique practice of localization, Ciji set up a "cash for work" program to help people clean up their own communities and earn a living at the same time. It was the brainchild of Zhengyan herself. Ciji may have many volunteers, but the cleanup work was too much for the volunteers to undertake on their own. By paying 10,000 locals to do the work under their supervision, the cleanup and rebuilding job was done in three weeks' time with the added benefit of providing dignity to all the participants. They were not simply recipients of aid but had a direct hand in rebuilding their communities.

The money put in the hands of people also served to support the local economy. People went to the stores and bought what they really needed that was not in the relief packs given to them. In 2013, when Typhoon Haiyan ravaged Tacloban City, the same cash for work program was established to help the city rebuild. One beneficiary shared that he lost everything in the typhoon and needed to buy underwear, but this was not a standard inclusion in relief packages. With the money he earned from the cash for work program, he was able to buy his own underwear, support a local shop, and help rebuild his community. Everybody benefited.

The year 2013 was particularly difficult for the Philippines. Even before Typhoon Haiyan came in November, the city of Zamboanga in Mindanao had been the setting for armed conflict between insurgents and the Philippine army in August. There was a large-scale displacement of people, and Ciji's center there sprang into action. In October, a strong earthquake hit the island of Bohol, destroying centuries-old churches and displacing many people. It was then that Ciji volunteers provided relief and established a new office there.

Haiyan, the strongest typhoon in recorded history, came in November, hitting several areas of the central Philippines. Eighty percent of the infrastructure of Tacloban was de- 
stroyed, corpses were lying on the streets, and survivors were in a daze, not knowing what to do. The national government took time to organize relief, but Ciji immediately mobilized and sustained their operations for two months, distributing hot meals, installing water purifiers, conducting medical missions, and constructing temporary shelters. Volunteers from thirteen countries took turns working on site, and donations were solicited in 46 countries. Zhengyan took a personal interest in the operations and was updated daily about developments.

In a variation of the cash for work program, Zhengyan saw the urgency of the situation in the first days of rebuilding and decided to give cash to help the survivors with their immediate needs. She knew that the donated funds would not be enough to sustain the people and rebuild their homes as well, so she decided to give cash first for immediate relief. Families of two were given 8000 pesos (US\$160), those with three or four members received 12,000 (US\$240), and bigger families received 15,000 pesos (US\$300). Both government officials and residents were shocked at this generosity, for it had never happened before that such amounts of cash were so easily dispensed. After all, relief operations usually distributed goods rather than cash. To the critics who saw it as a waste of money, Zhengyan said that it was just like a deep well of water; one must put in a little water to get the water flowing out.

The economic revival of the city was sparked by the cash for work program. After providing initial relief, the task of rebuilding had to be undertaken. Where there was despair, a sense of hope was cultivated as people were empowered to rebuild their city while also receiving a daily incentive. Starting with their own backyards, then moving to common areas, people worked for weeks to clean up and rebuild, each day receiving more than the minimum wage for their daily sustenance. For nineteen days, up to 300,000 people worked to clean up seventy villages, the biggest cleanup effort in the history of Ciji.

Ciji did not leave Tacloban, Leyte, after the relief and rebuilding operations. Two Great Love Villages were constructed to provide housing to displaced residents-255 houses in Palo, Leyte, and 1585 in Ormoc, Samar. Zhengyan personally supervised the design of each house, saying that the houses given to survivors must be "one we are willing to live in." The cash for work program contributed the necessary manpower for such a massive construction project. In Tacloban, Ciji provided 50 million pesos (US\$1 million) to restore the St. Niño Catholic Church, an effort that Zhengyan highlighted because she felt that the people needed their faith to sustain them through the hard times. Archbishop John Du recalls Zhengyan's words: "Your church is the pillar in the city and should be restored soonest" (Honasan 2019, p. 173).

Ciji volunteers also conducted livelihood training sessions to equip people with skills. Proper waste segregation systems were put up. To inaugurate the villages, Ciji gifted each household with items needed in daily life. Following local customs, a Catholic service was conducted to bless the new homes. Years after Haiyan reduced much of Leyte and Samar into wastelands, Ciji continued to visit and transfer technology so that what they started could be sustained.

Ciji has been holistic in its approach to social work. While the "eight footprints" mentioned earlier as the mission of Ciji can be undertaken by any group, Ciji Philippines is unique for being unfazed by the many constraints of working in a developing country. The cash for relief and cash for work programs are particularly strong examples of localization in the Philippine setting, efforts made possible by a transnational network that ensured the flow of funds and materials from both local and foreign sources.

Many have wondered whether Ciji tries to convert local people into Buddhism. After all, each day of volunteer work begins with talks on the teachings of Zhengyan and some Buddhist ideas. However, just like the work of Foguangshan, there is no program for religious conversion in Ciji, and many activities are directed at supporting and collaborating with the work of the Catholic Church. 


\section{Conclusions}

The works of Foguangshan and Ciji in the Philippines, focused on education, culture, and charity, are success stories for the spread of Buddhist modernism in general, and humanistic Buddhism in particular. Both movements have embraced particular needs in the contemporary context of the Philippines and utilized all modern means at their disposal to respond. This kind of logic in the way Foguangshan and Ciji developed in the Philippines is characteristic of the Buddhist modernism described by Lopez (2002), McMahan (2008), among others, and signals the first phase of their localization in the Philippines.

Unfazed by the COVID-19 pandemic, both continue to move forward with their missions. Foguangshan's Guang Ming College moved to a new campus under new leadership. Ciji has been actively working to mitigate the effects of the pandemic, distributing food and providing medical supplies and equipment to the neediest hospitals in the country. When Typhoon Rai (local name Odette) brought extensive damage to the Central Visayas and Northern Mindanao regions in December 2021, both groups mobilized to contribute to relief and rehabilitation work. ${ }^{8}$

To say that Foguangshan and Ciji utilize Buddhist modernist approaches in localization is a basic premise that I have demonstrated, but this is by no means the end of the story. In the case of Foguangshan, two of my informants, So (2021) and Tan (2021), noted how the translation of ideas into local languages is still at a very preliminary stage. Notwithstanding the success of Foguangshan in the last thirty years, establishing itself in four Philippine cities and founding a school granting undergraduate degrees, the materials used for the Philippine audience have been largely in Chinese and English. The latter was a breakthrough for the Chinese Buddhism in the country that hitherto operated only in the Chinese-speaking community, but Foguangshan members themselves can see that localization requires translation into local languages. It is true that English is widely spoken and understood, but it is still a foreign language. Politicians and priests understand this very well. They know that they cannot win elections or connect at a deeper level by communicating only in English.

I noted earlier that the teachings of Ciji founder, Zhengyan, have begun to be translated into Tagalog, again an indication that while charitable projects can proceed despite the language barrier, propagating teachings will require more than the use of modern technology. In my interview with Lao (2021), she shared that all Ciji activities begin with a short introduction of the group to the beneficiaries, but finding the right person to do the job is a challenge. Their leaders and officers can communicate in English and Chinese, but cannot connect easily with the economically poor. Lao shared that because most of their members are ethnically Chinese, beneficiaries at first think they are Koreans or Japanese until they are heard speaking informally in local languages. When Ciji is introduced as originating in Taiwan, beneficiaries think of Thailand. These experiences point to the importance of making Ciji look and sound more Filipino in its future development.

It is enlightening to note that Catholicism, with five centuries behind it in the Philippines, could penetrate the country only with the help of massive translation work. Rafael (1988) provides a seminal analysis of the strong links between translation, conversion, and nationalism. Spanish missionaries painstakingly learned and preserved Philippine languages, but translating religious tracts and colonial structures was a process that combined religious and political objectives. In a later work (Rafael 2005), Rafael focuses on the reverse process when the local people, who spoke different languages owing to their islands of origin, promote the idea of nationhood against Spain by using Castilian Spanish as their common language. He argues that translation into and use of Castilian was key to the development of Filipino nationalism.

Considered against this backdrop, the role of translation during centuries of Spanish rule is perhaps indicative of the long road ahead for Foguangshan and Ciji in their engagement of Filipinos, although both do not have conversion as an objective. 
To use an example from Buddhist Studies, Schedneck's (2015) study of international meditation centers in Thailand analyzes how these centers engaged with Buddhist modernity and translated traditions of Buddhist meditation for a non-Thai audience. These centers offered two tracks for learning meditation, one for Thais who saw it as part of a broader set of Buddhist beliefs and practices, and another for foreigners who sought meditation for personal growth and healing. Given the assumptions of the latter group, the centers translated meditation techniques to respond to the foreigner's needs. Schedneck carefully points out that this approach is part and parcel of Buddhism's historical and worldwide development, always translating to new languages and adapting to particular contexts.

This calls to mind the Chinese face of humanistic Buddhism. Considered from a wider perspective, the encounter between the ethnic Chinese members of Foguangshan and Ciji and other Filipinos is one that was made possible by adequate, if not ideal, linguistic links. However, just as Thai meditation needed to be translated for a non-Thai audience, there is a dynamic process unfolding where Chinese humanistic Buddhism is slowly being translated into Philippine languages and structures. Apart from translating texts into local languages, I see practices such as Buddhist weddings and bathing the Buddha ceremonies, which find their parallels in Filipino Catholic devotions and practices, as part of the process of translation.

Foguangshan wants to make its mark in culture and education, envisioning the growth of humanistic Buddhism in the country. Miaojing says that the temple services will continue as the spiritual base of Foguangshan activities, but it is humanistic Buddhism that will grow through cultural and educational endeavors rather than a program that identifies Chinese or Filipino Buddhism as a religion (Shih 2021).

For his part, Qua (2021), who has joined Ciji missions in other countries like Indonesia and Iran, is confident that Ciji will continue under younger leadership. Both Ciji and Foguangshan are aware that a major period of transition will come when their respective founders pass away, but they are not daunted by the future. While their works may look very Chinese in structure and style, I would conclude that this is seen as a step in their development as movements and organizations. The humanistic Buddhism of Foguangshan and Ciji will keep evolving for as long as it responds to the concrete needs of people in all the places where they operate.

The initial localization of Foguangshan and Ciji in the Philippines was made possible not only by their volunteers' generosity, flexibility, and creativity to respond to local needs but also by their positive attitude towards other religions, especially the Catholic Church to which the majority of Filipinos belong. Both are explicit in prohibiting proselytization, although overzealous members may at times give the impression that this is part of their agenda. The links that both have forged with Catholic groups in the Philippines have allowed their work to be perceived as non-sectarian and interreligious, making participation in their projects an attractive option for non-Chinese Filipinos. In a highly westernized society like that of the Philippines, this too is a significant departure from the neat sectarianism of western thinking and recalls the nine indicators of Buddhist modernism outlined by Lopez (2002). These include the focus on Buddhism as a philosophy, a distaste for superstition and elaborate rituals, the strong role of women and laity, and attention to social welfare, all elements that can be clearly discerned in the work of Foguangshan and Ciji in the Philippines.

Concerns about funding and organization, and prospects for the future, are acknowledged, but the localization in the Philippines will continue and take on new forms as the twenty-first century unfolds. The dynamics of Buddhist modernism, responding to specific contexts using the latest technology while remaining faithful to core Buddhist ideas, will continue to develop. After all, the 25 to 30 years of history that Ciji and Foguangshan have clocked in the Philippines are but drops in the vast ocean of humanistic Buddhism. 
Funding: The APC was funded by the Rizal Library Open Access Journal Publication Grant, Loyola Schools, Ateneo de Manila University.

Institutional Review Board Statement: Not applicable.

Informed Consent Statement: Informed consent was obtained from all subjects involved in the study.

Data Availability Statement: Not applicable.

Conflicts of Interest: The author declares no conflict of interest.

\section{Notes}

1 The ethnic Chinese community comprises only 1-2\% of the Philippine population, and the majority, or $82 \%$, identify as Christians (Ang-See 1997, p. 57). The statistics, however, do not reflect actual religious practice due to religious syncretism, i.e., the reality of Chinese Catholics who also participate in Chinese Buddhist temple life. My earlier work profiled 37 such temples.

2 Information on the history of Foguangshan in the Philippines is from Chapter 2 of my 2015 book, Chinese Buddhism in Catholic Philippines. There is a series of videos produced by Foguangshan that documents their history in the country; and also a forthcoming book to mark their 30th anniversary in the Philippines (2020). The Manila temple's name is a play on Chinese and Buddhist ideas, wannian means ten thousand years, while mabuhay is a Tagalog-Filipino greeting which means "long live!".

3 The Foguangshan Philippines website (https:/ / mabuhaytemple.com/three-acts-of-goodness-2, accessed on 10 January 2022) is not updated. Detailed information came from the interview with Shih (2021).

4 "Establishing the Characteristics of Humanistic Buddhism", in Happily Ever After: Hsing Yun's Hundred Sayings Series Vol. 3 (Taipei: Fo Guang Shan Board of Directors, 1999, p. 213), quoted in Shih (2020, pp. 114-15).

$5 \quad$ I interviewed So (2021), a Buddhist youth leader at the Mabuhay Temple.

6 The story of Ciji in the Philippines is documented in a picture book entitled A Mission of Love by Alya B. Honasan, who was commissioned to write the book to mark Ciji's 25th anniversary in the country (2019). Detailed information on Ciji programs in the wake of typhoon Haiyan are from Yolanda in Focus: Ciji Disaster Relieffor Typhoon Haiyan (Taipei: Ciji Publications, 2014) and Resurgence: Ciji Disaster Relief for Typhoon Haiyan (Taipei: Ciji Publications, 2017).

7 The ten precepts are made up of eight prohibitions against killing, stealing, fornicating, lying, drinking alcohol, smoking or using prohibited drugs, gambling, and participating in political demonstrations; the two positive precepts are to be filial to parents/being gentle in demeanor and to follow traffic rules.

8 Among other articles on their social media pages, see https://www.tzuchi.org.ph/news/features-and-stories/hope-after-odette/ and https:/ / www.facebook.com/chuuntemple/posts/10165953680940176 (accessed on 11 January 2022).

\section{References}

Ang-See, Teresita. 1997. The Chinese in the Philippines: Problems and Perspectives. Manila: Kaisa Para sa Kaunlaran, vol. 2.

Chandler, Stuart. 2004. Establishing a Pure Land on Earth: The Foguang Buddhist Perspective on Modernization and Globalization. Honolulu: University of Hawaii Press.

Chia, Jack Meng-Tat. 2015. Toward a Modern Buddhist Hagiography: Telling the Life of Hsing Yun in Popular Media. Asian Ethnology 74: 141-65. [CrossRef]

Chia, Jack Meng-Tat. 2020. Monks in Motion: Buddhism and Modernity Across the South China Sea. New York: Oxford University Press.

Correa, Helen. 2021. Online video interview by Aristotle Dy. September 17.

Dy, Ari. 2015. Chinese Buddhism in Catholic Philippines: Syncretism as Identity. Manila: Anvil.

Hansen, Anne. 2007. How to Behave: Buddhism and Modernity in Colonial Cambodia, 1860-1930. Honolulu: University of Hawaii Press.

Heine, Steven, and Charles Prebish, eds. 2003. Buddhism in the Modern World: Adaptations of an Ancient Tradition. New York: Oxford University Press.

Honasan, Alya. 2019. A Mission to Love. Manila: Ciji Foundation, Inc.

Huang, C. Julia. 2009. Charisma and Compassion: Cheng Yen and the Buddhist Ciji Movement. Cambridge: Harvard University Press.

Huang, C. Julia. 2014. From Diasporic to Ecumenical: The Buddhist Tzu Chi (Ciji) Movement in Malaysia. In Proselytizing and the Limits of Religious Pluralism in Contemporary Asia. Edited by Juliana Finucane and R. Michael Feener. Singapore and Heidelberg: Springer, pp. 191-209.

Jones, Charles B. 2003. Transitions in the Practice and Defense of Chinese Pure Land Buddhism. In Buddhism in the Modern World: Adaptations of an Ancient Tradition. Edited by Steven Heine and Charles Prebish. New York: Oxford University Press, pp. 125-42.

Laliberté, André, and Manuel Litalien. 2010. The Tzu Chi Merit Society from Taiwan to Canada. In Wild Geese: Buddhism in Canada. Edited by John S. Harding, Victor Sogen Hori and Alexander Soucy. Montreal: McGill-Queen's University Press, pp. $295-320$.

Lao, Judy. 2021. Online video interview by Aristotle Dy. May 22.

Lau, Arnold Lindros, and Jayeel Serrano Cornelio. 2015. Tzu Chi and the Philanthropy of Filipino Volunteers. Asian Journal of Social Science 43: 376-99. [CrossRef] 
Lee, Jonathan H. X. 2003. Tzu Chi Compassion Society's Peace Work in America. The Journal of the International Association of Buddhist Universities 2: 145-64.

Lopez, Donald S., Jr. 2002. Modern Buddhism: Readings for the Unenlightened. London: Penguin.

McMahan, David L. 2008. The Making of Buddhist Modernism. New York: Oxford University Press.

Nakar, Nyanza, and Erika Vizcarra. 2010. First Filipino Tzu Chi Youth Still Thoughts Life Camp Touching the Hearts and Changing the Lives of the Youth. Tzu Chi Quarterly Publication. Available online: http:/ / bit.ly/SSMnD3 (accessed on 27 October 2021).

Pacey, Scott. 2005. A Buddhism for the Human World: Interpretations of Renjian Fojiao in Contemporary Taiwan. Asian Studies Review 29: 445-61. [CrossRef]

Qua, Josefino. 2021. Online video interview by Aristotle Dy. September 22.

Rafael, Vicente. 1988. Contracting Colonialism: Translation and Christian Conversion in Tagalog Society under Early Spanish Rule. New York: Cornell University Press.

Rafael, Vicente. 2005. The Promise of the Foreign: Nationalism and the Technics of Translation in the Spanish Philippines. Durham and London: Duke University Press.

Reinke, Jens. 2018. Sacred Secularities: Ritual and Social engagement in a Global Buddhist China. Religions 9: 338. [CrossRef]

Schedneck, Brooke. 2015. Thailand's International Meditaiton Centers: Tourism and the Global Commodification of Religious Practices. London and New York: Routledge.

Shih, Miaoguang. 2020. Issues of Acculturation and Globalization Faced by the Fo Guang Shan Buddhist Order. Studies on Humanistic Buddhism III: 107-34.

Shih, Miaojing. 2021. Online video interview by Aristotle Dy. September 22.

So, Scott. 2021. Online video interview by Aristotle Dy. June 16.

Tan, Michael L. 2021. Online video interview by Aristotle Dy. June 12.

Tan, Shiling. 2008. Religious Alternation, Spiritual Humanism: Tzu Chi Buddhist Foundation in Singapore. Master's Thesis, National University of Singapore, Singapore.

Wang, Bin. 2020. Fo Guang Shan's “Localization of Buddhism” within the Internationalization of Buddhism. Studies on Humanistic Buddhism III: 135-54.

Welch, Holmes. 1968. The Buddhist Revival in China. Cambridge: Harvard University Press.

Yao, Yu-shuang. 2012. Taiwan's Ciji as Engaged Buddhism. Leiden: Global Oriental. 